\title{
Reply to the comments by Falsetti et al.
}

\author{
T. Suzuki, H. Shirai
}

Division of Allergy and Rheumatology, Japanese Red Cross Medical Center, Tokyo, Japan

$\mathrm{D}$ ear Editor,

We would like to thank Falsetti and colleagues for their interest in our recent case report regarding subcalcaneal bursitis in very early rheumatoid arthritis (RA) patients $(1,2)$, and we provide our response to their comments as follows.

\section{DEFINITION AND NOMENCLATURE}

Although there is only limited literaturebased evidence, there are several textbooks and pictorial reviews describing plantar bursitis as adventitial (adventitious) bursitis, as they pointed out in their letter $(3,4)$. Therefore, we agree with their suggestion to use the term subcalcaneal adventitial bursitis.

\section{CAN SUBCALCANEAL} ADVENTITIAL BURSITIS BE CONSIDERED AN EQUIVALENT FOR SYNOVITIS?

On ultrasound, an adventitial bursitis usually appears as a poorly defined heterogeneous region without vascularization (5). In RA patients, however, adventitial bursitis often presents with power Doppler signals in the well-demarcated and thickened bursal wall. This observation makes us imagine that rheumatoid inflammation resembling synovitis has developed there, although an adventitial bursa essentially lacks a mesothelial lining and synovia. Histological data are needed for further discussion.

\section{IS SUBCALCANEAL ADVENTITIAL BURSITIS SPECIFIC FOR RHEUMATOID ARTHRITIS?}

We do not consider that subcalcaneal adventitial bursitis itself is specific for RA. However, we suppose that persistent inflammation in soft tissues other than articular synovium or tenosynovium can precede persistent synovitis at the onset of RA. We have previously reported cases of RA patients with a high ACPA titer whose initial manifestation of RA was paratenonitis or tendinitis $(6,7)$. It is intriguing to speculate that synovial membranes may not be necessary for the initiation of rheumatoid inflammation in the very earliest phase of the disease. Also from this point of view, a histopathological investigation of subcalcaneal adventitial bursitis that presented at the onset of RA is highly anticipated.

\section{REFERENCES}

1. Suzuki T, Shirai H. Subcalcaneal bursitis as the initial manifestation of rheumatoid arthritis: ultrasonographic observation of two cases. Reumatismo. 2020; 71: 230-4.

2. Falsetti P, Conticini E, Baldi C, et al. Observations about subcalcaneal adventitial bursitis (heel fat pad inflammatory lesion) in rheumatoid arthritis. Comment on article of Suzuki T. and Shirai H. Reumatismo. 2020; 72: [in press].

3. Studler U, Mengiardi B, Bode B, et al. Fibrosis and adventitious bursae in plantar fat pad of forefoot: MR imaging findings in asymptomatic volunteers and MR imaging-histologic comparison. Radiology. 2008; 246: 863-70.

4. Ruangchaijatuporn T, Gaetke-Udager K, 
Jacobson JA, et al. Ultrasound evaluation of bursae: anatomy and pathological appearances. Skeletal Radiol. 2017; 46: 445-62.

5. Filippini C, Teh J. Ultrasound features of sole of foot pathology: a review. J Ultrason. 2019; 19: 145-51.

6. Suzuki T, Ishihara K. Achilles paratendonitis as the initial manifestation of rheuma- toid arthritis. Mod Rheumatol. 2011; 21: 219-22.

7. Suzuki T, Okamoto A. Marked multiple tendinitis at the onset of rheumatoid arthritis in a patient with heterozygous familial hypercholesterolemia: ultrasonographic observation. Case Rep Rheumatol. 2014; 2014: 486348. 